\title{
ANFIS Modeling for Prediction of Particle Size in Nozzle Assisted Solvent-Antisolvent Process for Making Ultrafine CL-20 Explosive
}

\author{
Dinesh K. Pal ${ }^{1, a^{*}}$, Shallu Gupta ${ }^{1, b}$, Deepika Jindal ${ }^{1, \mathrm{c}}$, Anil Kumar $^{2, \mathrm{~d}}$, Arun Agarwal $^{1, \mathrm{e}}$ \\ and, Prem Lata ${ }^{3, f}$ \\ ${ }^{1}$ Terminal Ballistics Research Laboratory, DRDO, Sector-30 D, Chandigarh-160030, India \\ ${ }^{2}$ University Institute of Engineering and Technology, Panjab University, Hoshiarpur, India \\ ${ }^{3}$ Department of Applied Sciences, PEC University of Technology, Chandigarh-160 014, India \\ adineshpalb@yahoo.com, bshallugupta74@yahoo.com, cfrn.deepika@gmail.com, \\ deed.tbrl@gmail.com, earun907@yahoo.com, fprem_lata36@yahoo.com
}

\section{Keywords: Ultrafine CL-20, Artificial Neural Network, ANFIS, Neuro-Fuzzy}

\begin{abstract}
Physical properties such as particle size, surface area and shape of explosive control the rapidity and reliability of initiation, and detonation and thus determine the performance of an explosive device such as slapper detonators. In this paper, Nozzle assisted solvent/antisolvent (NASAS) process for recrystallisation of CL-20 explosive is established. Many process parameters are involved which affect the particle size of the explosive. Therefore an accurate prediction of particle size is required to tailor the particle size. In the present work, an intelligent algorithm is applied to build a simplified relationship between recrystallization process parameters and particle size. This can be used to predict explosive particle size with a wide range of process parameters through an adaptive neuro-fuzzy inference system(ANFIS). The model is trained using experimental data obtained from design of experiment techniques utilizing a MATLAB software. Six process parameters such as Solution pressure, Antisolvent pressure, Antisolvent temperature, Stirrer speed, Solution concentration and Nozzle diameter are used as input variables of the model and the particle size is used as the output variable. The predicted results are in close agreement with experimental values and the accuracy of the model has been tested by comparing the simulated data with actual data from the explosive recrystallization experiments and found to be inacceptable range with maximum absolute percentage error of $11.52 \%$. The ultrafine CL-20 prepared by NASAS process is used in Slapper detonator application. The threshold initiation voltages for CL-20 based slapper detonator is found to be in the range of $0.9 \mathrm{kV}$ with standard deviation of $\pm 0.1 \mathrm{kV}$.
\end{abstract}

\section{Introduction}

The physical properties such as crystal particle size, shape, morphology, crystalline imperfections, purity and microstructure of the inter-crystalline voids of an existing explosive can be altered. There are wide variety of processes available for tailoring particle size and morphology of energetic materials such as solvent/non-solvent recrystallization[1],continuous crystallization of submicrometer energetic materials [2], spray flash evaporation [3]Yang et al. [4] obtained nanoTATB by using solvent/anti-solvent method with a particle size of $60 \mathrm{~nm}$ approximately through atomization of solution by a nozzle to small droplets and colliding rapidly with non-solvent flow. There is a need of mathematical model to predict particle characteristics as a function of process parameters to provide a basis for a computer based process control system. Shallu Gupta et al.[5,6], used micro nozzle assisted spraying process (MNASP) for recrystallization of Submicrometer Hexanitrostilbene (sm-HNS) Explosive. The process attributes were optimized using weighted average techniques of Analytical Network Process (ANP). The advantages of neural network based 
techniques include extreme computation, powerful memory and rapid learning from experimental data. Furthermore, it can predict an output parameter with accuracy even if the input parameter interactions are not completely understood[7, 8]. Artificial neural network (ANN) and multilayer perceptron (MLP) is widely established inartificial intelligence (AI) research where a nonlinear mapping between input and output parameters is required for a function approximation[9, 10]. Pannier et. al, have explained the application and general features of Fuzzy logic (FL)modeling, fuzzy sets, membership functions, and fuzzy clustering[11]. theoretical details of the neuro-fuzzy modeling can be found in $[12,13]$. Moreover, however, relevant features and context that refer to the adopted means of neuro-fuzzy modeling, i.e., ANFIS [14]

It is seen from literature that in spite of being powerful modeling tool, ANFIS has not been used in the study of explosive recrystallization process. A neuro-fuzzy technique called adaptive network based fuzzy inference system (ANFIS) combines fuzzy systems with neural networks, utilizing the learning characteristics of neural network and decision making capability of fuzzy systems. In this research work, application of ANFIS model is adopted for predicting the particle size of CL-20 explosive in solvent-antisolvent recrystallization process.

\section{Experimental Work}

The explosive material used in this research work was raw $\varepsilon$-CL-20 with a particle size in the range of 50 to $60 \mu \mathrm{m}$. In this research work, for making UF-CL20, a Nozzle Assisted Solvent-Antisolvent (NASAS) process has been designed, developed, fabricated and installed, as per schematic diagram shown in Fig. 2. The NASAS process was used to carry out 49 experiments for making UF-CL20 explosive. Based on design of experiments, six input parameters were considered which affect the output of the re-crystallized explosive i.e. particle size. The input parameters are - solution pressure, anti-solvent pressure, anti-solvent temperature, stirrer speed, solution concentration and nozzle diameter. The output parameter i.e. particle size was used as the response variable. The UF-CL20 obtained by NASAS process was characterized as explained in the following section.

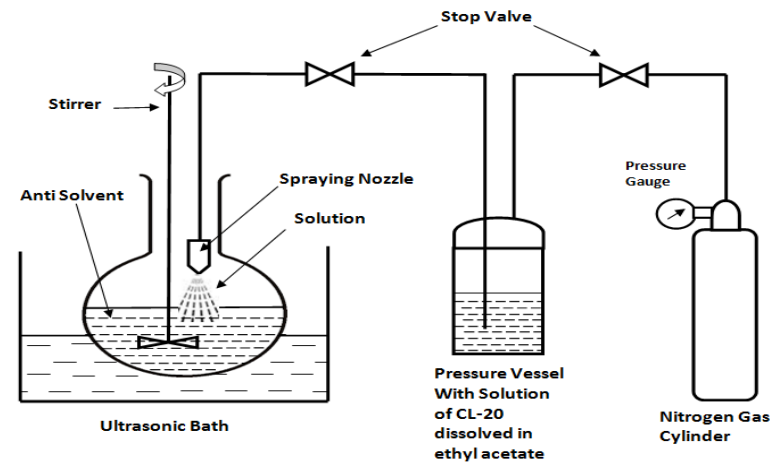

Figure 1. Schematic of NASAS process

\section{Characterization}

The distribution of particle size for some of the samples under similar condition is shown in Fig. 3 with mean particle size of UF-CL20 as $2.61 \mu \mathrm{m}$ with standard deviation of $0.242 \mu \mathrm{m}$. Total 42 Nos. of experiments were carried out to record the 42 data of input-output pairs of variables shown in Table 1 for ANFIS model. Recrystallised ultrafine CL-20 was characterized using XRD analysisto ensure crystalline nature XRD pattern showed the peaks at similar difraction angle as those of CL20 which exhibits a unique non-overlapping diffraction peak at 19.98 20, as shown in Fig.4. FTIR analysis was carried out to ensure there is no change in molecular structure after processing as shown in Fig.5. SEM photography showed the reduction of particle size and the morphology was 
also affected by the process parameters as shown in Fig. 6. The shape is a mix of polyhedral and nearly spherical geometry. The surface seems to be smooth with negligible defects/ cracks.

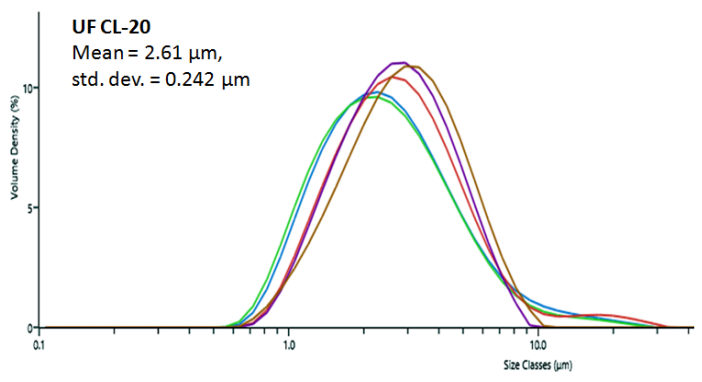

Figure 2. Particle size distribution

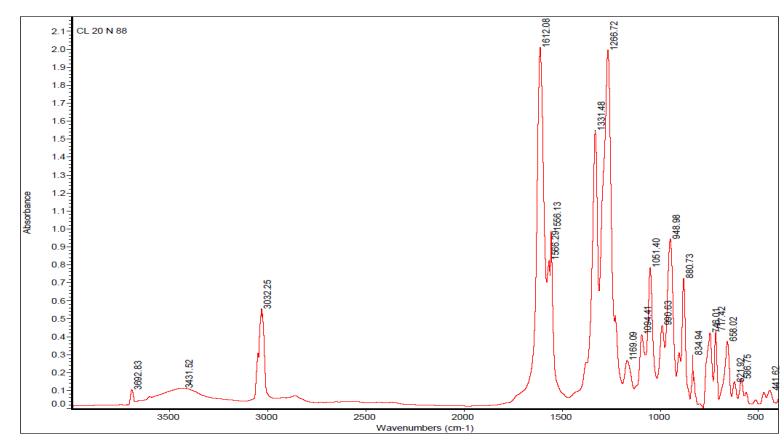

Figure 4. FTIR Analysis

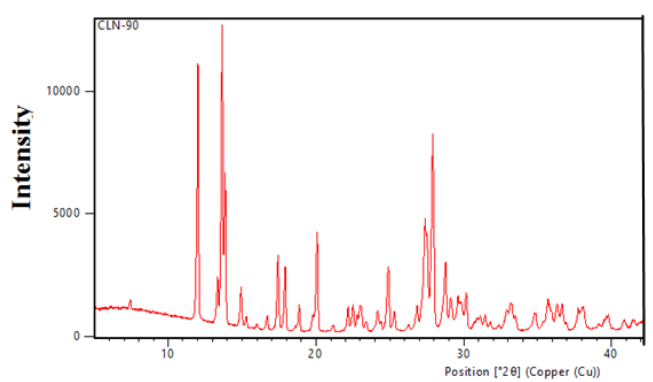

Figure 3. XRD pattern of processed CL20

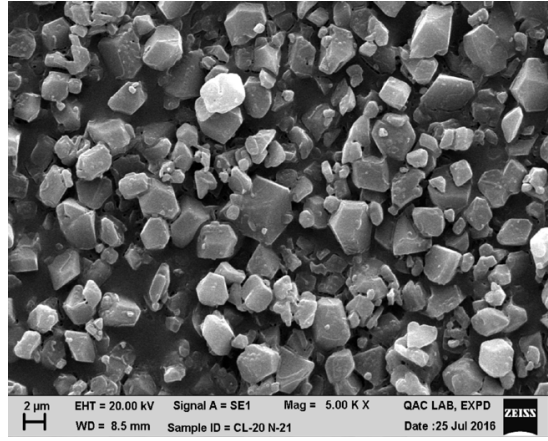

Figure 5. SEM microphotograph

Table 1. Experimental data of particle size

\begin{tabular}{|c|c|c|c|c|c|c|c|c|}
\hline $\begin{array}{c}\text { Run } \\
\text { Order }\end{array}$ & $\begin{array}{c}\text { Experime } \\
\text { nt }\end{array}$ & $\begin{array}{c}\text { Solutio } \\
\mathrm{n} \\
\text { Pressur } \\
\text { e (bar) }\end{array}$ & $\begin{array}{c}\text { Antisolve } \\
\text { nt } \\
\text { Pressure } \\
(\text { bar })\end{array}$ & $\begin{array}{c}\text { Antisolvent } \\
\text { Temperature } \\
\left({ }^{\circ} \text { C) }\right.\end{array}$ & $\begin{array}{c}\text { Stirrer } \\
\text { Speed } \\
(\mathrm{RPM})\end{array}$ & $\begin{array}{c}\text { Solution } \\
\text { Concentrati } \\
\text { on } \\
(\%)\end{array}$ & $\begin{array}{c}\text { Nozzle } \\
\text { Diameter } \\
(\mathrm{mm})\end{array}$ & $\begin{array}{c}\text { Particl } \\
\text { e Size } \\
(\mu \mathrm{m})\end{array}$ \\
\hline 1 & $\mathrm{~N}-19$ & 6 & 6 & -9 & 800 & 5 & 0.7 & 5.63 \\
\hline 2 & $\mathrm{~N}-20$ & 7 & 7 & -9 & 800 & 5 & 0.7 & 5.77 \\
\hline 3 & $\mathrm{~N}-26 \mathrm{~A}$ & 5 & 1 & 30 & 1010 & 10 & 0.7 & 4.19 \\
\hline 4 & $\mathrm{~N}-45$ & 5 & 1 & 0 & 1010 & 10 & 0.7 & 2.38 \\
\hline 6 & $\mathrm{~N}-33$ & 6 & 1 & 30 & 500 & 5 & 1.0 & 10.34 \\
\hline 7 & $\mathrm{~N}-77$ & 7 & 1 & 20 & 1020 & 10 & 0.5 & 8.67 \\
\hline 8 & $\mathrm{~N}-94$ & 6 & 1 & 20 & 1020 & 10 & 0.4 & 6.48 \\
\hline 10 & $\mathrm{~N}-26$ & 2 & 3.5 & 30 & 600 & 10 & 0.7 & 50.3 \\
\hline 11 & $\mathrm{~N}-29$ & 4 & 1 & 45 & 500 & 10 & 0.7 & 7.62 \\
\hline 12 & $\mathrm{~N}-50$ & 2 & 1 & 0 & 1080 & 10 & 0.7 & 14.2 \\
\hline 13 & $\mathrm{~N}-51$ & 2 & 1 & 13 & 1080 & 10 & 0.7 & 5.89 \\
\hline 14 & $\mathrm{~N}-24$ & 4 & 1 & -2 & 800 & 5 & 1.0 & 3.76 \\
\hline 16 & $\mathrm{~N}-23$ & 6 & 1 & -2 & 800 & 5 & 1.0 & 4.35 \\
\hline 17 & $\mathrm{~N}-25$ & 6 & 1 & 30 & 800 & 5 & 1.0 & 8.93 \\
\hline 18 & $\mathrm{~N}-32$ & 1 & 1 & 35 & 500 & 10 & 1.0 & 22.5 \\
\hline 19 & $\mathrm{~N}-34$ & 2 & 1 & 9 & 500 & 10 & 1.0 & 9.31 \\
\hline
\end{tabular}




\begin{tabular}{|c|c|c|c|c|c|c|c|c|}
\hline 20 & $\mathrm{~N}-35$ & 4 & 1 & 9 & 500 & 10 & 1.0 & 8.1 \\
\hline 22 & $\mathrm{~N}-31$ & 2 & 1 & 35 & 500 & 10 & 1.0 & 4.74 \\
\hline 23 & $\mathrm{~N}-36$ & 1 & 1 & 11 & 500 & 10 & 0.55 & 5.72 \\
\hline 25 & $\mathrm{~N}-28$ & 1 & 1 & 45 & 1120 & 10 & 0.55 & 19.8 \\
\hline 26 & $\mathrm{~N}-55$ & 1 & 1 & 10 & 1120 & 10 & 0.55 & 6.92 \\
\hline 27 & $\mathrm{~N}-62$ & 6.2 & 1 & 20 & 1040 & 10 & 0.5 & 7.05 \\
\hline 28 & $\mathrm{~N}-68$ & 6.5 & 1 & 20 & 1700 & 10 & 0.5 & 8.52 \\
\hline 29 & $\mathrm{~N}-66$ & 7 & 1 & 20 & 1700 & 10 & 0.5 & 5.34 \\
\hline 30 & $\mathrm{~N}-79$ & 6 & 1 & 15 & 1800 & 10 & 0.5 & 5.15 \\
\hline 31 & $\mathrm{~N}-80$ & 6.2 & 1 & 15 & 1500 & 10 & 0.5 & 6.03 \\
\hline 33 & $\mathrm{~N}-53$ & 2 & 1 & 10 & 1120 & 10 & 0.7 & 24.0 \\
\hline 34 & $\mathrm{~N}-82$ & 6 & 1 & 15 & 1500 & 10 & 1.5 & 21.3 \\
\hline 35 & $\mathrm{~N}-83$ & 6 & 1 & 10 & 1100 & 10 & 0.5 & 4.51 \\
\hline 36 & $\mathrm{~N}-87$ & 6 & 1 & 0 & 1100 & 10 & 0.5 & 3.40 \\
\hline 37 & $\mathrm{~N}-88$ & 6 & 1 & 0 & 1100 & 10 & 0.5 & 4.67 \\
\hline 39 & $\mathrm{~N}-93$ & 6 & 1 & 19 & 1020 & 10 & 0.5 & 8.0 \\
\hline 40 & $\mathrm{~N}-95$ & 6 & 1 & 20 & 1080 & 10 & 0.4 & 5.77 \\
\hline 41 & $\mathrm{~N}-97$ & 6 & 1 & 15 & 1020 & 10 & 0.4 & 11.1 \\
\hline 42 & $\mathrm{~N}-98$ & 6 & 1 & 5 & 1040 & 10 & 0.4 & 16.9 \\
\hline
\end{tabular}

Table 2. Experimental testing data

\begin{tabular}{|c|c|c|c|c|c|c|c|c|}
\hline $\begin{array}{c}\text { Run } \\
\text { Order }\end{array}$ & $\begin{array}{c}\text { Exper } \\
\text { iment }\end{array}$ & $\begin{array}{c}\text { Solutio } \\
\mathrm{n} \\
\text { Pressur } \\
\mathrm{e}(\mathrm{bar})\end{array}$ & $\begin{array}{c}\text { Antisolve } \\
\mathrm{nt} \\
\text { Pressure } \\
(\mathrm{bar})\end{array}$ & $\begin{array}{c}\text { Antisolvent } \\
\text { Temperature } \\
\left({ }^{\circ} \mathrm{C}\right)\end{array}$ & $\begin{array}{c}\text { Stirrer } \\
\text { Speed } \\
(\mathrm{RPM} \\
)\end{array}$ & $\begin{array}{c}\text { Solution } \\
\text { Concentration } \\
(\%)\end{array}$ & $\begin{array}{c}\text { Nozzle } \\
\text { Diamete } \\
\mathrm{r}(\mathrm{mm})\end{array}$ & $\begin{array}{c}\text { Particle } \\
\text { Size } \\
(\mu \mathrm{m})\end{array}$ \\
\hline 5 & $\mathrm{~N}-30$ & 1 & 1 & 14 & 500 & 10 & 0.55 & 5.31 \\
\hline 9 & $\mathrm{~N}-44$ & 5 & 1 & 0 & 1010 & 10 & 0.70 & 2.69 \\
\hline 15 & $\mathrm{~N}-56$ & 1 & 1 & 06 & 1120 & 10 & 0.55 & 2.74 \\
\hline 21 & $\mathrm{~N}-60$ & 6 & 1 & 25 & 1040 & 10 & 0.50 & 2.57 \\
\hline 24 & $\mathrm{~N}-76$ & 7 & 1 & 22 & 1020 & 10 & 0.50 & 4.18 \\
\hline 32 & $\mathrm{~N}-52$ & 3 & 1 & 28 & 1120 & 05 & 0.70 & 2.92 \\
\hline 38 & $\mathrm{~N}-81$ & 6 & 1 & 13 & 1200 & 10 & 0.50 & 1.82 \\
\hline
\end{tabular}




\section{ANFIS Model Development}

ANFIS architecture based on the first-order Sugeno model is shown in Fig.7.ANFIS was implemented using Matlab (Version 8.1, 2013a, The Mathworks, Inc., USA). In particular, the Matlab Fuzzy Toolbox was adopted as the means for building ANFIS. The data matrix was structured in the form of seven columns, with the first six corresponding to the input variables and the seventh one to the output variable (response). Out of 49 data sets, 42 sets of data (Table 1) were used for training the ANFIS model and 07 dataset were used for testing the model (Table 2). After testing the testing data the experimental value and the ANFIS predicted value, Average Testing Error is 0.2431 . After the model is trained and tested, the rule viewer is used for finding the ANFIS output for any instance of input by just entering them at the bottom of the window as shown in Figure 8. For an instance when the six inputs 1, 1, 6, 1120, 10, 0.55 and output particle size predicted by the ANFIS is $2.54 \mu \mathrm{m}$.
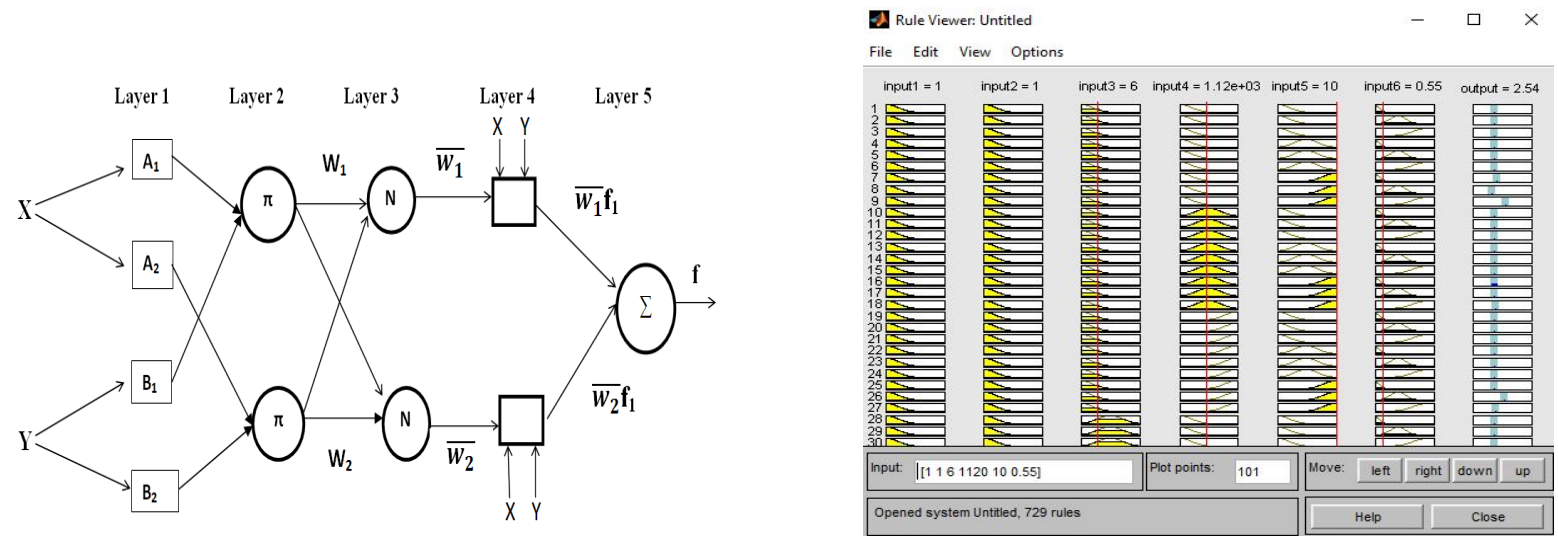

Figure 6. Schematic of ANFIS architecture based and ANFIS rule viewer

\section{Comparison of ANFIS Predicted Value and Experimental Value of Particle Size}

After training and testing the experimental data, the value of particle size, which is inbetween 1 to 6 $\mu \mathrm{m}$, is compared with the experimental value and ANFIS prediction value is shown in Table 4 . Actual error is the subtraction of experimental value and ANFIS prediction value. And Absolute Percentage Error is ratio of actual error to the experimental value as shown in Table 4.

Table 4. Comparison of Predicted and Experimental Particle Size Results

\begin{tabular}{|c|c|c|c|c|c|c|}
\hline \multirow{2}{*}{$\begin{array}{l}\text { Run } \\
\text { Order }\end{array}$} & \multirow{2}{*}{$\begin{array}{l}\text { Experim } \\
\text { ent }\end{array}$} & \multirow{2}{*}{$\begin{array}{l}\text { Nozzle } \\
\text { Diameter } \\
(\mathrm{mm})\end{array}$} & \multicolumn{2}{|c|}{ Particle Size $(\mu \mathrm{m})$} & \multicolumn{2}{|l|}{ Error } \\
\hline & & & $\begin{array}{l}\text { Exp. } \\
\text { Value }\end{array}$ & $\begin{array}{l}\text { ANFIS } \\
\text { Prediction }\end{array}$ & $\begin{array}{l}\text { Actual } \\
\text { Error }(\mu \mathrm{m})\end{array}$ & $\begin{array}{l}\text { Absolute Percentage } \\
\text { Error (\%) }\end{array}$ \\
\hline 5 & $\mathrm{~N}-30$ & 0.55 & 4.86 & 5.31 & -0.45 & 09.25 \\
\hline 9 & $\mathrm{~N}-44$ & 0.70 & 2.69 & 2.38 & 0.31 & 11.52 \\
\hline 15 & $\mathrm{~N}-56$ & 0.55 & 2.74 & 2.54 & 0.20 & 07.29 \\
\hline 21 & $\mathrm{~N}-60$ & 0.50 & 2.57 & 2.81 & -0.24 & 09.33 \\
\hline 24 & $\mathrm{~N}-76$ & 0.50 & 4.18 & 4.06 & 0.12 & 02.87 \\
\hline 32 & $\mathrm{~N}-52$ & 0.70 & 2.92 & 2.96 & -0.04 & 01.36 \\
\hline 38 & $\mathrm{~N}-81$ & 0.50 & 1.82 & 1.77 & 0.05 & 02.74 \\
\hline
\end{tabular}




\section{Surface View of Particle Size}

Apart from its prediction efficiency, ANFIS revealsinformation about the system being modeled. This is evidenced by the three-dimensional diagrams of the response variable as a function of the causal factors (in pairs of two), as presented in Figure 12. From this figure, it is apparent that nonlinear relationships between the input process variables and the response variable were well represented with response surface predicted by ANFIS. It appears that ANFIS captures such relationships and could be used as a tool where approximations of such relationships are required.

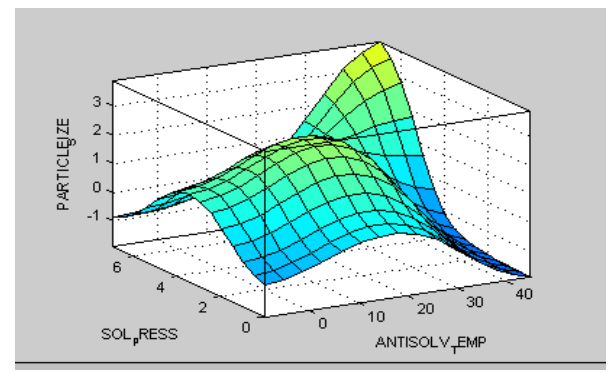

(a)

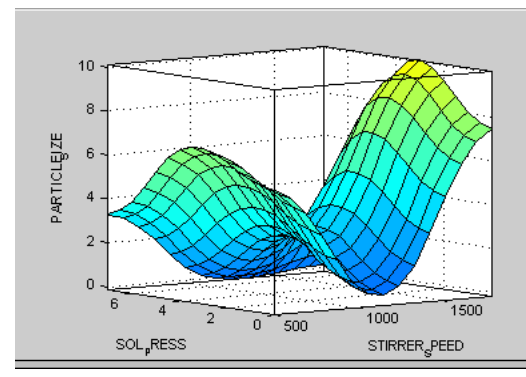

(b)

Figure 7. Surface response: (a) Solution pressure \& Antisolvent temp (b) solution pressure \& stirrer speed

\section{Application of UF-CL20 Explosive in Slapper Detonator}

In slapper detonator, prompt detonation of high density $(1.5 \mathrm{~g} / \mathrm{cc})$ pellet of ultrafine CL-20 occurs when a thin polyimide flyer is impacted. The flyer is launched to a velocity of $2-3 \mathrm{~km} / \mathrm{s}$ by electrically exploding foil when high electrical energy applied in short duration. It impacts the CL20 explosive leading to initiation by shock-to-detonation phenomenon.Experimental prototypes of slapper detonators were fabricated and threshold trials were carried out using Bruceton test. The threshold initiation voltage for CL-20 is the range of $0.9 \mathrm{kV}$ with standard deviation of $\pm 0.1 \mathrm{kV}$. The threshold initiation energy for CL-20 based slapper detonator is much lower than HNS-IV based slapper detonator.

\section{Conclusions}

The main advantage of NASAS process is recrystallization of ultrafine CL-20 explosive using solvent-antisolvent method. There exists nonlinear relationship between the input process variables and the output variable 'particle size'. Neuro-fuzzy technique 'ANFIS'was developed for capturing such relationships and predicting the particle size for a given set of input variables. The ANFIS model was trained and tested using experimental data. Maximum absolute percentage error between the predicted value and experimental value is $11.52 \%$ which is in acceptable range. The model will further become accurate when large amout of training data is used. Artifical Neural based techniques enable learning and improving process characteristics for obtaining desired and repeatable output. It is experimentally found that the ultrafine CL-20 explosive based Slapper detonator has a threshold of $0.9 \mathrm{kV} \pm 0.1 \mathrm{kV}$. It is a type of low energy exploding foil initiator which has a great potential for futuristic applications in miniaturized systems such as Fuzes for various munitions and warheads. 


\section{Acknowledgements}

The authors would like to gratefully thank Dr. Manjit Singh, Director TBRL for his support and encouragement. This research did not receive any specific grant from funding agencies in the public, commercial, or not-for-profit sectors.

\section{References}

[1] J. Wang, et al., Study on Ultrasound-and Spray-Assisted Precipitation of CL-20. Propellants, Explosives, Pyrotechnics, 37(6) (2012), 670-675. https://doi.org/10.1002/prep.201100088

[2] D. Spitzer, et al., Continuous crystallization of submicrometer energetic compounds, Propellants, Explosives, Pyrotechnics, 36(1) (2011), 65-74. https://doi.org/10.1002/prep.200900002 [3] M. Klaumünzer,J. Hübner, and D. Spitzer, Production of Energetic Nanomaterials by Spray Flash Evaporation, World Academy of Science, Engineering and Technology, International Journal of Chemical, Molecular, Nuclear, Materials and Metallurgical Engineering, 10(9) (2016), 11911195.

[4] G. Yang,et al., Preparation and Characterization of Nano-TATB Explosive, Propellants, Explosives, Pyrotechnics: An International Journal Dealing with Scientific and Technological Aspects of Energetic Materials, 31(5) (2006), 390-394. https://doi.org/10.1002/prep.200600053

[5] S. Gupta, D. K.Pal, et al., Pressurized Nozzle-Based Solvent/Anti-Solvent Process for Making Ultrafine $\epsilon$-CL-20 Explosive, Propellants, Explosives, Pyrotechnics, 42(7) (2017), 773-783. https://doi.org/10.1002/prep.201700002

[6] S. Gupta, et al., D. K. Pal, et. al., Micro Nozzle Assisted Spraying Process for Re-crystallization of Submicrometer Hexanitrostilbene Explosive, Propellants, Explosives, Pyrotechnics, 43 (7) (2018), 721-731. https://doi.org/10.1002/prep.201800008

[7] S. Singh, et al., Neural network analysis of steel plate processing, Iron making and Steelmaking, 25(5) (1998), 355-365.

[8] J. M. Vitek,Neural networks applied to welding: two examples, ISIJ international, 39(10) (1999), 1088-1095. https://doi.org/10.2355/isijinternational.39.1088

[9] I.S. Kim, et al., Optimal design of neural networks for control in robotic arc welding, Robotics and computer-integrated manufacturing, 20(1) (2004), 57-63. https://doi.org/10.1016/s07365845(03)00068-1

[10] S. Pal, S.K. Pal, and A.K. Samantaray, Artificial neural network modeling of weld joint strength prediction of a pulsed metal inert gas welding process using arc signals, Journal of $\begin{array}{lllll}\text { materials } & \text { processing } & \text { technology, } & \text { 202(1-3) }\end{array}$ https://doi.org/10.1016/j.jmatprotec.2007.09.039

[11] A.K.Pannier,R.M. Brand, and D.D. Jones, Fuzzy modeling of skin permeability coefficients, Pharmaceutical research, 20(2) (2003.), 143-148.

[12] J. Jang,Neuro-fuzzy modeling: architectures, analyses and applications [dissertation]. California: University of Berkeley, 1992.

[13] J. Hines,L.H. Tsoukalas, and R.E. Uhrig, MATLAB supplement to fuzzy and neural approaches in engineering, John Wiley \& Sons, Inc., 1997

[14] J. S. Jang, ANFIS: adaptive-network-based fuzzy inference system, IEEE transactions on systems, man, and cybernetics, 1993, 23(3), 665-685. https://doi.org/10.1109/21.256541 